\title{
Clinicians' consent law knowledge: The case for education
}

\author{
D. P. Craigi \& F. Thompson ${ }^{2}$
}

\begin{abstract}
Introduction: The short-term objectives of this study were to investigate clinicians' confidence with, and knowledge of, consent laws, their behaviour regarding familiarisation with patients' advance care plans and the potential benefit of brief education. Education covered patients' rights to refuse treatment, including via advance directive, and the legislated hierarchy of decision-making authority.

Methods: Throughout 2018, all clinicians at one Queensland Hospital and Health Service were invited to attend a 1-hour legal education session. The study used a crosssectional survey to measure clinicians' knowledge before and after education. Responses from 316 pre- and 319 post-education questionnaires were analysed.

Results: A 1-hour legal education session improved clinicians' understanding of legislated consent hierarchy and patients' rights. Pre education, $4.1 \%$ of participants correctly identified the lawful consent hierarchy, rising to $65.5 \%$ after education. Accuracy increased significantly after education; however, substantial errors persisted.

Conclusions: The potential benefit of education to increase multidisciplinary clinicians' legal knowledge was supported. Education can ensure that clinicians are made aware of patients' rights and the potential complexity of lawful substitute decision making.
\end{abstract}

Keywords: aging; advance care planning; advance directives; decision-making; medical education; legislation

Queensland Health, James Cook University

Australian Institute of Tropical Health and Medicine (AITHM), James Cook University

\section{Correspondence}

Denise Patricia Craig

Senior Psychologist FNQ Aged Care/Memory Clinic

Queensland Health

PO Box 1055

Cairns North, Queensland 4870

Australia

Tel: +61 742264595

Email: denise.craig@health.qld.gov.au 


\section{Introduction}

In Australia, statutory laws regulate patient consent to healthcare. These laws, which vary by state and territory, cover issues such as consent to receive, withhold or withdraw healthcare, whether an advance care plan (ACP) is binding and who is authorised to make treatment decisions. An ACP can express a person's values, beliefs and treatment preferences and is intended to guide clinical decision making (Sellars et al., 2015) and provide an individual with self-determination in healthcare until death (Royal Australian College of General Practitioners, 2012). In Queensland, competent adults have the right to record their healthcare choices within legally binding ACP documents—an enduring power of attorney (EPOA) and/or advance health directive (AHD), pursuant to the Powers of Attorney Act 1998 (Qld) and the Guardianship and Administrative Act 2000 (Qld). These powers are "enduring" because the decision will endure despite a person's later loss of decision-making capacity. Enduring documents can be used to nominate proxy healthcare decision makers and provide an adult with a means of consenting to the provision or withholding of future healthcare. These documents are powerful tools that should be understood by patients/proxies/families and clinicians.

Doctors are key partners in medical decision making, making their understanding of healthcare consent laws essential. Research has highlighted gaps in doctors' knowledge (Cartwright, White, et al., 2016; Parker et al., 2015; White, Willmott, Cartwright, Parker, \& Williams, 2015, 2016; White, Willmott, Cartwright, et al., 2017; White, Willmott, Williams, et al., 2017; Willmott, White, Close, et al., 2016) and tensions between legislation and "ethics", such as doctors' preference for a flexible, family and/or clinical decision-making model (Burkle et al., 2012; Cartwright, Montgomery, et al., 2014; Corke et al., 2009; White, Willmott, Williams, et al., 2017; Willmott, White, Close, et al., 2016; Willmott, White, Parker, et al., 2016; Willmott, White, Tilse, \& Wilson, 2013; Wong et al., 2012). Despite the obligation (in non-urgent situations) to obtain lawful consent to provide healthcare, doctors are reported to have poor understanding of legislated substitute decision-making authority (Cartwright, White, et al., 2016; White, Willmott, Cartwright, Parker, \& Williams, 2015), and many do not routinely review ACP records that represent their patients' prior treatment choices (Cartwright, Montgomery, et al., 2014; Wong et al., 2012). Doctors primarily claim ethical reasons (e.g., patient-related clinical factors) for end-of-life healthcare decision making (Burkle et al., 2012; Corke et al., 2009; White, Willmott, Cartwright, Parker, \& Williams, 2016; White, Willmott, Williams, et al., 2017; Wong et al., 2012) and appear to have limited knowledge of ACP-related law (Cartwright, Montgomery, et al., 2014). These issues may result in the denial of patients' rights and leave doctors at risk of complaint. One theme throughout the above literature is the suggestion by researchers that legal education for doctors should be increased.

Whilst competent patients have the right to autonomy, they are often reliant on the advice of their doctors when consenting to healthcare. Therefore, doctors are rightly perceived as key contributors in complex healthcare decisions. All clinicians, however, bear responsibility to act within relevant legislation. End-of-life healthcare legal education for clinicians appears to be gaining support, e.g., End of Life Law for 
Clinicians online training modules (White, Willmott, Yates, et al., 2019); however, engagement in education historically has been inconsistent (Parker et al., 2015). Without training, clinicians may unintentionally deny patient rights, yet Queensland Health does not provide mandatory legal education or routinely ensure clinicians understand their responsibilities. Accordingly, clinicians' knowledge and the potential benefit of targeted legal education is unknown and remains to be investigated.

A 1-hour education session was developed and delivered by the Hospital and Health Service senior legal counsel in conjunction with the first author (an aged care specialist clinician). The content of the education included introductory level patient rights relevant to AHD, EPOA and substitute decision maker (SDM) consent. The education also included case scenarios and an opportunity for questions. Throughout 2018, 35 sessions were provided within Hospital and Health Service venues (hospital, community and videoconference facilities) at a range of times to accommodate as many clinicians as possible. Hospital and Health Service executives and managers encouraged clinicians to attend.

The aim of this study was to assess the usefulness of a 1-hour education session in increasing clinicians' knowledge of patient consent legislation. The short-term objectives were to investigate clinicians' confidence with, and knowledge of, consent laws, their behaviour regarding familiarisation with patients' ACPs and the potential benefit of brief education. This study appears to be the first to explore clinicians' understanding of commonly encountered aspects of Queensland legislation relating to EPOA, AHD and consent.

\section{Methods}

\section{Study design and participants}

The study was a cross-sectional survey of clinicians' consent law confidence and knowledge before and after 1 hour of education. Between February and November 2018, all clinicians $(-4,000)$ in the North Queensland region Hospital and Health Service were invited to participate via Hospital and Health Service newsletters and emails. Of these, $\mathrm{n}=-535$ (13\% of Hospital and Health Service clinicians) attended and were invited to complete a knowledge questionnaire immediately before and after the education and an overall post-session satisfaction questionnaire. Attendance rates ranged between 3 and 70 per session, and some groups were not surveyed as anonymity was compromised by small group size. Remote area participants accessed sessions via video conference and entered data directly into an online SurveyMonkey questionnaire (SurveyMonkey Inc., San Mateo, California, USA). A total of 778 questionnaires (combined pre and post) were returned from participants. The participants were community and acute sector clinicians from medicine, nursing, social work, psychology, occupational therapy and physiotherapy who were working within the regional and remote Hospital and Health Service facilities. As this was a quality improvement activity, exemption from ethics approval was obtained from the Far North Queensland Human Research Ethics Committee (HREC/18/QCH/31 - 1206 QA). Face-to-face attendees signed consent 
forms, whilst online participants consented as a part of the online survey process. Under section 279A of the Queensland Public Health Act (2005), unidentifiable participant data will be made available upon request.

In $18.1 \%$ of all questionnaire responses, one or more of the nine knowledge questions were not attempted. These incomplete questionnaires were excluded, resulting in a sample size of 635 responses. Within this sample, there were $316(59 \%)$ responses from clinicians pre education and 319 (59.6\%) post education. While there was considerable overlap in participants between these groups, data were unable to be linked at an individual level between groups, and the groups were not identical in terms of membership. For example, some clinicians who completed the pre-education questionnaire did not go on to provide a post-education questionnaire and some clinicians who completed the post-education questionnaire were "new" to the study and did not provide a pre-education questionnaire.

\section{Survey instruments}

Questionnaires were designed by the first author in consultation with Hospital and Health Service senior legal counsel. Participants could leave questions blank and still progress through the questionnaire, which took approximately 6 minutes to complete. Paper-based questionnaire data were later entered into SurveyMonkey Inc. by the first author and an assistant.

The pre-education questionnaire comprised 13 questions of closed categorical, Likertscale and free-text response formats. Included was a vignette (Cartwright, White, et al., 2016; White, Willmott, Cartwright, Parker, \& Williams, 2016) that asked participants to choose between an estranged husband, son (EPOA for finances), daughter/carer, same-sex partner and a public guardian for SDM consent. Content was divided into six sections: 1) participant familiarity with EPOA/AHD, 2) confidence with EPOA/ AHD, 3) beliefs about a person's right to refuse treatment, 4) knowledge of the legislated hierarchy for SDM consent, 5) the role of appointed health attorneys and 6) any additional comment. Figure 1 (below) shows the Queensland legislated order of priority for consent to healthcare, which was used to inform questions on SDM consent. The post-education questionnaire altered one question to assess clinicians' intention to routinely familiarise themselves with EPOA/AHD in future, and all other questions remained the same.

Participant responses were anonymised, and no personal identifiers or demographic information were collected.

\section{Data analysis}

Pre- and post-education data were not linked at an individual level. To accommodate this study design during analyses, participants were considered as members of two mutually-exclusive groups, and tests for differences between independent samples were used. Results for categorical and dichotomous variables are presented as proportions. All continuous variables had skewed distributions, and results are presented as medians (med) with interquartile ranges (iqr). 
MULTIDISCIPLINARY CONSENT LAW EDUCATION

\section{Figure 1}

Legislative Hierarchy of Substitute Decision Makers for Adults With Impaired Capacity

\section{Adults with impaired capacity:}

Order of priority for dealing with health matter consent

Guardianship and Administration Act 2000 (Old), s66, and Powers of Attorney Act 1998 (Old) s63.

1. Advance Health Directive if a direction about the matter was made.

2. Tribunal appointed guardian for the matter.

3. Attorney/s appointed in most recent enduring document.

4. Statutory Health Attorney. The first of the following people who is readily available and culturally appropriate:

a. Spouse if the relationship is close and continuing

b. An adult who has the care of the adult and is not a paid carer of the adult

c. An adult who is a close friend or relation and not a paid carer of the adult

\section{Public Guardian}

The distribution of proportions between the pre- and post-education groups (Table 1) were examined using $\mathrm{Chi}^{2}$ analyses. Fischer's exact tests were used when any cell had less than five observations. Continuous variables were compared between these same groups using Wilcoxon rank-sum tests. Spearman's rank correlation was used to examine the relationship between confidence and knowledge within each group. A $p$-value less than 0.05 was considered significant. All analyses were undertaken in Stata 14 software package (Stata Corp, College Station, Texas, USA).

\section{Results}

Prior to education, half (49.1\%) of all participants reported routinely familiarising themselves with patients' EPOA/AHD (Table 2). There was a significant correlation between confidence with EPOA documents and knowledge of laws and rights for the clinicians both before (Spearman's Rho $=0.249, p<0.001$ ) and after (Spearman's Rho $=0.124, p=0.028)$ education.

Knowledge scores for clinicians post education $(\operatorname{med}=8$, iqr $=7-9)$ were significantly higher than pre education (med $=6$, iqr $=5-7)(z=-16.9, p<0.001)$ (Table 1). Similarly, the proportion of clinicians who answered all nine knowledge questions correctly post education $(\mathrm{n}=130,40.1 \%)$ was substantially greater compared to pre education $(n=5,1.5 \%$, Figure 2). Participant satisfaction questionnaire data indicated a high degree of satisfaction with the program (data not tabled).

\section{Competent patients' right to refuse treatment}

Before the education, $98.7 \%$ of participants agreed a patient has a right to refuse treatment. This result was comparable post education $(p=0.185$, Table 1$)$. If patient death could occur sooner as a result of refusing treatment, acknowledgement of the patient's refusal right reduced for clinicians pre education $(94.0 \%)$ and not post education $(99.4 \%)$. If the patient's refusal rationale was disagreeable or withheld, 
MULTIDISCIPLINARY CONSENT LAW EDUCATION

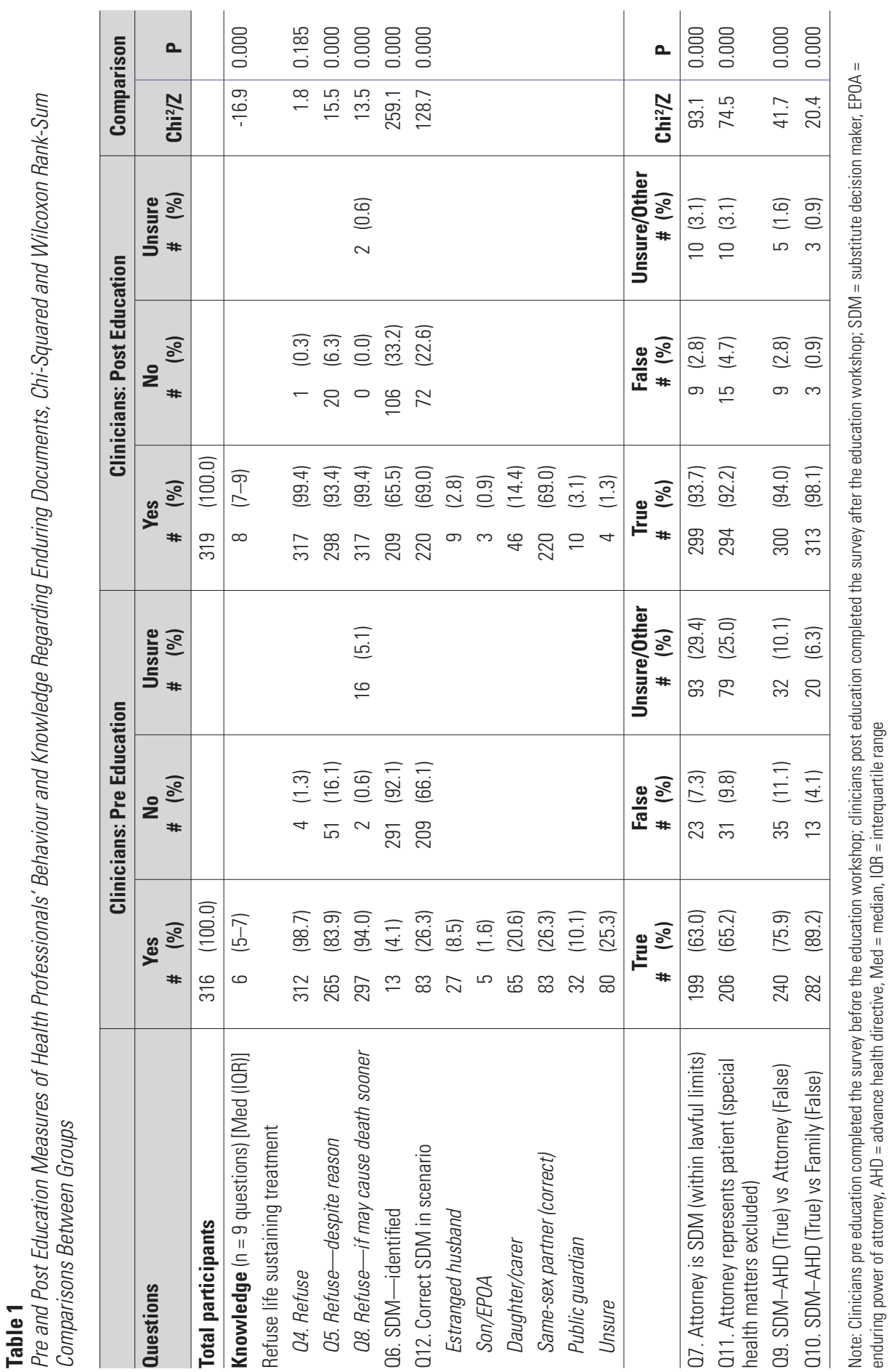




\section{MULTIDISCIPLINARY CONSENT LAW EDUCATION}

\section{Figure 2}

Number of Correct Knowledge Questions, by Education Group

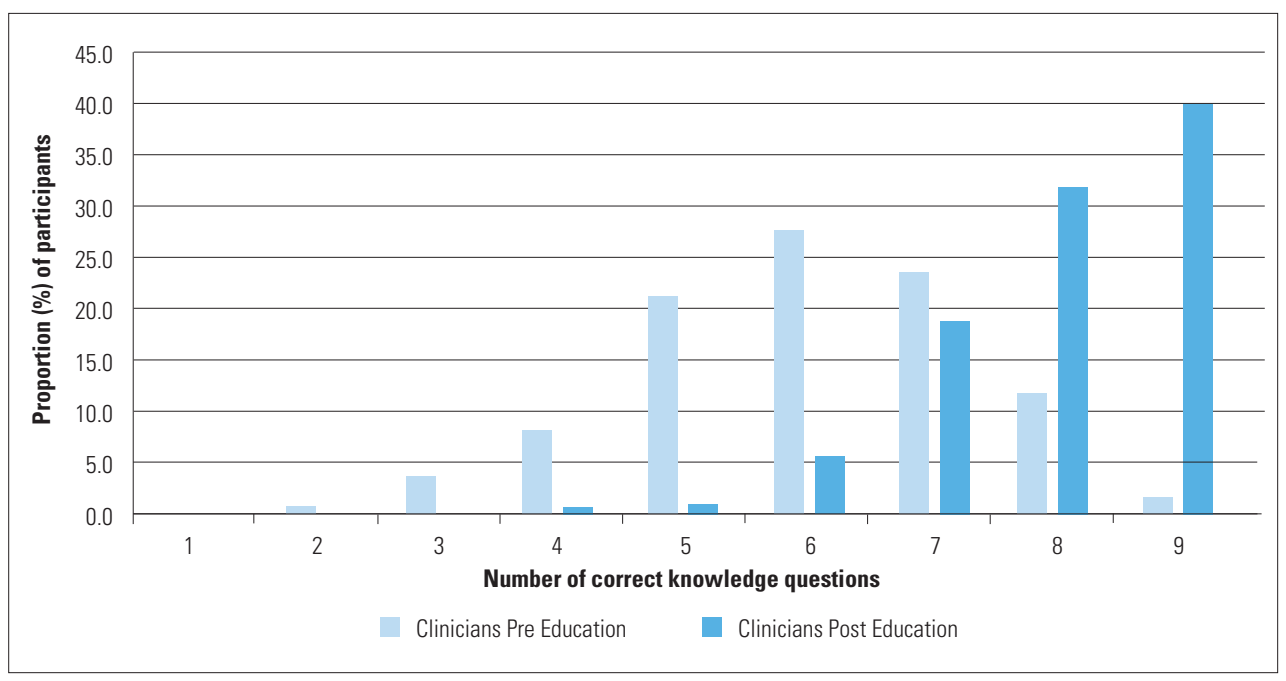

Table 2

Pre and Post Education Measures of Health Professionals' Confidence Regarding Enduring Documents, ChiSquared and Wilcoxon Rank-Sum Comparisons Between Groups

\begin{tabular}{|c|c|c|c|c|c|c|}
\hline \multirow[b]{2}{*}{ Questions } & \multicolumn{2}{|c|}{$\begin{array}{l}\text { Clinicians: } \\
\text { Pre Education }\end{array}$} & \multicolumn{2}{|c|}{$\begin{array}{l}\text { Clinicians: } \\
\text { Post Education }\end{array}$} & \multicolumn{2}{|c|}{ Comparison } \\
\hline & $\#$ & $(\%)$ & $\#$ & $(\%)$ & $\mathrm{Chi}^{2} / \mathrm{Z}$ & $\mathbf{P}$ \\
\hline Total participants & 316 & $(100.0)$ & 319 & $(100.0)$ & & \\
\hline \multicolumn{7}{|l|}{ Behaviour ( $n=1$ question) } \\
\hline 01. Familiarise with EPOA/AHD & 155 & (49.1) & 283 & (88.7) & 131.9 & $<0.001$ \\
\hline \multicolumn{7}{|c|}{$\begin{array}{l}\text { Confidence levels ( } n=2 \text { questions) } \\
\text { 02. Confidence with EPOA }\end{array}$} \\
\hline$[\operatorname{Med}(I Q R)]$ & 3 & $(2-4)$ & 4 & $(4-4)$ & -11.5 & $<0.001$ \\
\hline (1) Not confident & 39 & (12.3) & 3 & $(0.9)$ & 142.2 & $<0.001$ \\
\hline (2) A little & 89 & (28.2) & 18 & (5.6) & & \\
\hline (3) Neutral & 65 & (20.6) & 35 & $(11.0)$ & & \\
\hline (4) Moderate & 96 & (30.4) & 202 & (63.3) & & \\
\hline (5) Very confident & 19 & (6.0) & 55 & $(17.2)$ & & \\
\hline \multicolumn{7}{|l|}{ 03. Confidence with AHD } \\
\hline [Med (IQR)] & 3 & $(2-4)$ & 4 & $(4-5)$ & -12.9 & $<0.001$ \\
\hline (1) Not confident & 39 & (12.3) & 3 & $(0.9)$ & 171.3 & $<0.001$ \\
\hline (2) A little & 98 & $(31.0)$ & 20 & (6.3) & & \\
\hline (3) Neutral & 70 & (22.2) & 32 & $(10.0)$ & & \\
\hline (4) Moderate & 87 & (27.5) & 173 & $(54.2)$ & & \\
\hline (5) Very confident & 15 & $(4.7)$ & 82 & (25.7) & & \\
\hline
\end{tabular}

Note: Clinicians pre education completed the survey before the education workshop; clinicians post education completed the survey after the education workshop; $\mathrm{SDM}=$ substitute decision maker, $\mathrm{EPOA}=$ enduring power of attorney, $\mathrm{AHD}=$ advance health directive, Med = median, $\mathrm{IQR}=$ interquartile range 
MULTIDISCIPLINARY CONSENT LAW EDUCATION

acknowledgement of refusal right reduced to $83.9 \%$ pre education, which was significantly different post education (93.4\%, $p<0.001$, see Table 1 ).

\section{Legislated substitute decision maker consent}

When asked to correctly order the five consent options for an adult without decisionmaking capacity (see Figure 1), only $4.1 \%$ of clinicians were able to do so before education, compared to $65.5 \%$ of clinicians after education $(p<0.001$, Table 1$)$. When asked to choose from a given SDM scenario, only $26.3 \%$ of participants without education identified the lawful SDM compared to $69.0 \%$ post education $(p<0.001)$.

\section{Role of appointed bealth attorneys}

Over half (63.0\%) of participants pre education and almost all (93.7\%) post education agreed that an appointed health attorney is the lawful SDM $(p<0.001$, Table 1$)$. Three quarters $(75.9 \%)$ of participants pre education and almost all $(94.0 \%)$ post education indicated they would prioritise the AHD over a request from an attorney $(p<0.001)$. A high proportion of both these groups $(89.2 \%$ and $98.1 \%$, respectively) indicated they would prioritise the AHD over the request of a family member $(p<0.001)$.

\section{Discussion}

The aim of this study was to assess the usefulness of a 1-hour education session aimed at increasing clinicians' knowledge of consent laws. The objectives were to investigate whether clinicians routinely familiarise themselves with their patients' ACPs and measure consent law confidence and knowledge before and after a specifically designed education program. Overall, results indicate clinicians often did not familiarise themselves with ACPs and they had inadequate understanding of some aspects of the law relating to EPOA, AHD and consent. Knowledge scores were positively correlated to confidence and were significantly higher among clinicians who had attended an education session, although substantial errors in identification of SDMs persisted.

This study revealed a strong linear correlation between clinician confidence and mean correct scores. This result supports the findings of White, Willmott, Cartwright, Parker and Williams (2016) and suggests that clinicians who are most confident do typically hold higher level knowledge of law in relation to EPOA/AHD and consent. Despite this, most of the confident participants made errors relating to treatment refusal rights and/or the legal hierarchy for the provision of consent. Confidence and knowledge were significantly higher among participants who attended the education session, indicating that targeted education can help to address critical knowledge gaps, at least in the short term.

Patients who provide ACPs to a hospital and health service as a means of exercising their right to autonomy surely have expectations that clinicians will review and respect their documented choices. It seems possible, however, that this does not consistently occur. Fifty percent of clinicians reported not routinely familiarising themselves with ACPs. Many participants spoke of difficulty accessing ACPs and/or that ACPs are the domain of doctors and social workers. Of note, treating clinicians are not required by legislation 
to proactively seek documented ACPs, and enduring authority commences only if the patient is unable to provide direct consent. Accordingly, many clinicians would not perceive a need to initiate a review of an ACP; however, post education, clinicians reported increased intention to do so. Improved legal knowledge appears to encourage clinicians to review documentation, which is likely to improve the patient-clinician partnership and healthcare outcomes.

A competent patient's right to refuse healthcare is considered a fundamental right in most Western nations. In this study, almost all participants agreed that a competent person has the right to refuse life-sustaining healthcare; however, they were less likely to agree when the patients' rationale was considered of poor quality or if no rationale was offered at all. After education results improved, however, a surprising proportion of clinicians continued to indicate insufficient understanding about limitations to the rights of a competent patient to refuse treatment. It seems likely that clinicians at times evaluate patients' reasons and deny rights where differences of opinion or values occur, making further education to all clinicians critical.

Almost no clinicians correctly identified the legislated healthcare consent hierarchy when the patient cannot consent directly. These data support earlier findings and recommendations for education (Cartwright, Montgomery, et al., 2014; Parker et al., 2015; White, Willmott, Cartwright, Parker, \& Williams, 2015, 2016; Willmott, White, Parker, et al., 2016). Whilst correct results increased significantly after education, one third of clinicians continued to make substantial errors, such as listing the statutory health attorney first, the AHD last and/or an enduring health attorney as a low priority. Patients could rightly expect hospital and health services and clinicians to have appropriate knowledge and diligent consent procedures in place; however, this may not be the case. We suggest incorporating introductory legal information within orientation programs and procedure documents, as well as providing mandatory education to all clinicians as a matter of priority.

With AHD prevalence relatively low (White, Tilse, et al., 2014), it is often statutory decision makers who are required to consent to healthcare. Accordingly, participants were presented with a vignette and asked to choose the lawful decision maker. Before education, one quarter of participants were unsure and only $26 \%$ recognised the partner as the lawful decision maker. The estranged husband and public guardian were endorsed by $9 \%$ and $10 \%$ of respondents, respectively. Some respondents chose two or three people (e.g., partner, daughter and son) to act together, suggesting they felt unable to choose between these close contacts. Whilst correct responses post education increased and "unsure" responses reduced to near zero, incorrect responses persisted. Results indicate that clinicians continued to hold fixed or false beliefs, and they potentially accept unlawful consent in some circumstances, in breach of patient rights. Life and death decisions made by unlawful proxies leave patients and families at risk of substantial discontent and clinicians and the hospital and health service at risk of formal complaint. 


\section{Implications}

The potential benefit of education to increase clinicians' knowledge of consent law was supported in this study.

Several strategies are recommended to assist clinicians and patients to partner in healthcare. Relevant education should be provided regularly, and hospital and health services should ensure that all procedures and consent documents reflect the legislative order for consent. Clinicians should ascertain the legal substitute decision maker/s (not "next of kin") and staff should be provided with tools (e.g., lanyard card) to help clarify the lawful order for consent. Patient goals and ACPs should be reviewed regularly. Associated outcomes should be monitored and strategies adjusted as required.

\section{Limitations}

This study constituted a quality improvement activity within one hospital and health service; however, we believe it makes a worthwhile contribution to the investigation of potential benefits of clinician legal education. Improvement in knowledge long term was not tested. Whilst the survey instruments were designed in consultation with knowledge experts (including a senior doctor), no pilot study or item validation occurred. Participants could skip items, resulting in incomplete questionnaires being excluded from analyses, which may have biased the study sample towards confident participants who were willing to answer every question. Responses for individuals were not linked, and there was not complete continuity between participants in the pre and post groups (i.e., not all participants in the pre-education group went on to provide a post-education response). As a result, within-person change from pre to post education was not investigated. To enhance anonymity, this study did not seek demographic, discipline or experience data, so demographic analysis was not achievable. The results warrant further research focusing on clinicians' legal knowledge and associated education needs, and the extent to which information is retained over a longer period.

\section{Conclusion}

To our knowledge, this is the first study of its type to explore clinicians' understanding of Queensland's consent laws before and after tailored education. Understanding clinician knowledge and discerning a worthwhile education strategy are critical to ensure that patients' right to self-determination is observed and not disrupted by clinicians who are unaware of associated rights and responsibilities. Patients may also survive illness against their will, perhaps with the burden of additional incapacity. Most notably, this study identified a high level of misunderstanding among clinicians about a patient's right to refuse treatment and the legislated hierarchy for consent. Substantial gains were achieved after 1 hour of targeted education. Given the national accreditation standards of high-level comprehensive care for patients attending health facilities (Australian Commission on Safety and Quality in Health Care, 2014), we recommend that legal education addressing consent law and patients' rights to receive, withhold or withdraw healthcare be provided to all clinicians as a matter of priority. 


\section{Acknowledgements}

We would like to acknowledge the support of the Hospital and Health Service legal team, Drs Desley Harvey and Elizabeth Tynan, for meticulous editorial advice, Hospital and Health Service librarians who provided literature search support and Hospital and Health Service executives and clinicians who prioritised legal education and completed the surveys.

\section{Funding and conflict of interest statement}

This initiative received no external funding, and the authors report no conflicts of interest.

\section{References}

Australian Commission on Safety and Quality in Health Care. (2014). The National Safety and Quality Health Service (NSQHS) standards. In Comprehensive Care Standard. Author.

Burkle, C. M., Mueller, P. S., Swetz, K. M., Hook, C. C., \& Keegan, M. T. (2012). Physician perspectives and compliance with patient advance directives: The role external factors play on physician decision making. BMC Medical Ethics, 13, Article 31. https://doi.org/10.1186/1472-6939-13-31

Cartwright, C., Montgomery, J., Rhee, J., Zwar, N., \& Banbury, A. (2014). Medical practitioners' knowledge and self-reported practices of substitute decision making and implementation of advance care plans. Internal Medicine Journal, 44(3), 234-239. https://doi.org/10.1111/imj.12354

Cartwright, C. M., White, B. P., Willmott, L., Williams, G., \& Parker, M. H. (2016). Palliative care and other physicians' knowledge, attitudes and practice relating to the law on withholding/withdrawing life-sustaining treatment: Survey results. Palliative Medicine, 30(2), 171-179. https://doi.org/10.1177/0269216315587996

Corke, C., Milnes, S., Orford, N., Henry, M. J., Foss, C., \& Porter, D. (2009). The influence of medical enduring power of attorney and advance directives on decision-making by Australian intensive care doctors. Critical Care and Resuscitation, 11(2), 122-128. https://search.ebscohost.com/login.aspx?direct=true \&AuthType=ip,athens\&db=mdc\&AN=19485876\&site=ehost-live

Parker, M., Willmott, L., White, B., Williams, G., \& Cartwright, C. (2015). Medical education and law: Withholding/withdrawing treatment from adults without capacity. Internal Medicine Journal, 45(6), 634-640. https://doi.org/10.1111/ imj. 12759

Royal Australian College of General Practitioners. (2012). Position statement: Advance care planning should be incorporated into routine general practice. https://www.racgp.org.au/advocacy/position-statements/view-all-positionstatements/clinical-and-practice-management/advance-care-planning 
Sellars, M., Detering, K. M., \& Silvester, W. J. (2015). Current advance care planning practice in the Australian community: An online survey of home care package case managers and service managers. BMC Palliative Care, 14(1), Article 15. https://doi.org/10.1186/s12904-015-0018-y

White, B., Tilse, C., Wilson, J., Rosenman, L., Strub, T., Feeney, R., \& Silvester, W. (2014). Prevalence and predictors of advance directives in Australia. Internal Medicine Journal, 44(10), 975-980. https://doi.org/10.1111/imj.12549

White, B., Willmott, L., Cartwright, C., Parker, M. H., \& Williams, G. (2015). Doctors' knowledge of the law on withholding and withdrawing life-sustaining medical treatment. Medical Journal of Australia, 202(2), 77. https://doi. org/10.5694/mja14.01363

White, B., Willmott, L., Cartwright, C., Parker, M., \& Williams, G. (2016). The knowledge and practice of doctors in relation to the law that governs withholding and withdrawing life-sustaining treatment from adults who lack capacity. Journal of Law and Medicine, 24, 356-370.

White, B. P., Willmott, L., Cartwright, C., Parker, M., Williams, G., \& Davis, J. (2017). Comparing doctors' legal compliance across three Australian states for decisions whether to withhold or withdraw life-sustaining medical treatment: Does different law lead to different decisions? BMC Palliative Care, 16(1), Article 63. https://doi.org/10.1186/s12904-017-0249-1

White, B. P., Willmott, L., Williams, G., Cartwright, C., \& Parker, M. (2017). The role of law in decisions to withhold and withdraw life-sustaining treatment from adults who lack capacity: A cross-sectional study. Journal of Medical Ethics, 43(5), 327-333. https://doi.org/10.1136/medethics-2016-103543

White, B., Willmott, L., Yates, P., Shih-Ning, T., \& Neller, P. (2019). End of life law for clincians. https://end-of-life.qut.edu.au/

Willmott, L., White, B., Close, E., Gallois, C., Malcolm, P., Graves, N., Winch, S., Callaway, L., \& Shepherd, N. (2016). Futility and the law: Knowledge, practice and attitudes of doctors in end of life care. QUT Law Review, 16(1), 55-75. https://doi.org/10.5204/qutlr.v16i1.622

Willmott, L., White, B., Gallois, C., Parker, M., Graves, N., Winch, S., Callaway, L., Shepherd, N., \& Close, E. (2016). Reasons doctors provide futile treatment at the end of life: A qualitative study. Journal of Medical Ethics, 42(8), 496-503. https://doi.org/10.1136/medethics-2016-103370

Willmott, L., White, B., Parker, M., Cartwright, C., \& Williams, G. (2016). Is there a role for law in medical practice when withholding and withdrawing lifesustaining medical treatment? Empirical findings on attitudes of doctors. Journal of Law and Medicine, 24(2), 342-355. https://eprints.qut.edu. au/102166/9/102166.pdf 
MULTIDISCIPLINARY CONSENT LAW EDUCATION

Willmott, L., White, B., Tilse, C., \& Wilson, J. (2013). Advance health directives:

Competing perceptions, intentions and use by patients and doctors in Queensland. QUT Law Review, 13(1), 30-51. https://doi.org/10.5204/qutlr. v13i1.532

Wong, R. E., Weiland, T. J., \& Jelinek, G. A. (2012). Emergency clinicians' attitudes and decisions in patient scenarios involving advance directives. Emergency Medicine Journal, 29(9), 720-724. https://doi.org/10.1136/emermed-2011-200287 